\title{
PERCEPCIÓN LOCAL ACERCA DE LA CALIDAD DEL AGUA Y LA HERPETOFAUNA EN FINCAS GANADERAS DEL MUNICIPIO DE MATIGUÁS, NICARAGUA
}

\author{
Mario J. Gómez-Martínez \\ Isabel Gutiérrez-Montes ${ }^{2}$ \\ Fabrice Declerck ${ }^{3}$
}

Recibido el 26 de julio de 2013 y aprobado el 3 de septiembre de 2013

\section{RESUMEN}

Las percepciones de los productores ganaderos respecto a su bienestar, la calidad del agua y la diversidad de herpetofauna fueron examinadas usando entrevistas semiestructuradas a los productores y a las instituciones locales. Las entrevistas se utilizaron para desarrollar indicadores enmarcados en los capitales de la comunidad y validados a través de cuatro talleres. Los resultados indicaron que los productores tienen percepciones similares respecto a las relaciones entre la calidad del agua y la biodiversidad. Los productores comentaron que la cantidad de agua ha ido disminuyendo, aunque la mayoría de los productores no perciben una relación entre la calidad del agua, la salud humana o la salud del ganado. Hubo una ausencia significativa de las instituciones locales, la promoción y la financiación de proyectos de conservación de la biodiversidad, el acceso y almacenamiento de agua. En cuanto a la herpetofauna, las respuestas de los productores se han centrado en las funciones medicinales, alimenticias y controladores biológicos que estos organismos proveen. La mayoría de los productores entrevistados afirmaron que la incorporación de sistemas silvopastoriles en fincas ofrece beneficios, incluida la mejora de la calidad del agua y la conservación de la biodiversidad agrícola. Los productores demostraron conocimientos locales en la ubicación de las fuentes de agua y el uso tradicional de la herpetofauna.

\section{PALABRAS CLAVE}

Anfibios, biodiversidad, capital natural, conocimiento local, Marco de los Capitales de la Comunidad, reptiles.

\section{LOCAL PERCEPTIONS ABOUT WATER QUALITY AND HERPETOFAUNA IN LIVESTOCK FARMS IN THE MUNICIPALITY OF MATIGUÁS, NICARAGUA}

\begin{abstract}
Perceptions of livestock producers regarding their welfare, water quality and herpetofauna diversity were examined using semistructured interviews with farmers and local institutions. Interviews was used to develop indicators framed in community capitals and validated through four workshops. The results indicated that producers have similar perceptions of the relationships between water quality and biodiversity. Producers indicated that the amount
\end{abstract}


of water has been declining, although most producers do not perceive a relationship between water quality, human health or livestock health. There was a significant absence of: local institutions, biodiversity conservation projects promotion and financing, access and water storage. Regarding the herpetofauna, the' responses of producers have focused on medicinal, nutritional functions and biological regulation that these organisms provide. Most farmers interviewed stated that the incorporation ogf agroforestry systems on offers benefits including improved water quality and conservation of agricultural biodiversity. Farmers demonstrated local knowledge in locating water sources and in the traditional use of herpetofauna.

\section{KEY WORD}

Amphibians, biodiversity, natural capital, local knowledge, Community Capital Framework, reptiles.

\section{INTRODUCCIÓN}

Nicaragua es un país que basa su economía nacional en el sector agropecuario (café, algodón, ganadería, azúcar, madera) (ONU, 2005), producto de la explotación de la riqueza biológica en diferentes regiones naturales (Walsh, 1999). Estas actividades económicas no obedecen a un plan de organización y son carentes de criterios de sostenibilidad (MARENA, 2002). En productores marginales, el modelo de producción predominante los obliga a ocupar zonas no aptas para la producción agrícola y pecuaria, lo que se manifiesta en la expansión de las áreas agrícolas, ocasionando una marginalidad mayor debido a la intensificación de procesos de degradación de la tierra, erosión del suelo y sequía, entre otros factores (Cupples, 2004).

En zonas como el Pacífico de Nicaragua donde se ubica la mayor densidad poblacional agrícola e industrial, se presentan casos de explotación excesiva de los acuíferos y degradación progresiva de la calidad del agua, que amenaza la disponibilidad futura del recurso hídrico para la población (Castillo et al., 2006). En otras zonas como el centro del país, donde se ubica el triángulo lechero (departamentos de Boaco, Chontales y Matagalpa), el uso del suelo cambia a través de los años, presentando una tendencia a disminuir las áreas de bosques primarios y secundarios, mientras que aumentan las áreas de potreros, cultivos y urbanas (Rocha, 2002). Es importante entonces conocer la problemática del impacto de la ganadería en la conservación del agua, e identificar los factores que desmotivan a los productores en la toma de conciencia y decisiones que favorezcan el manejo de las microcuencas (Chará, 2003), además de fortalecer el bienestar de los productores (realidad socioeconómica) para un desarrollo sostenible de los agroecosistemas (Plieninger y Wilbrand, 2001).

En este sentido, los sistemas silvopastoriles (SSP) son estrategias sostenibles y amigables con el ambiente en las fincas ganaderas (Naranjo, 2003). Pueden representar beneficios para la 
conservación de la diversidad biológica, la prestación de servicios ambientales y el fortalecimiento del bienestar de las familias ganaderas (Harvey y Haber, 1999; Dagang y Nair, 2003; Pagiola et al., 2004). Además, son ideales en el mantenimiento y protección de los recursos hídricos de la matriz agrícola, que tradicionalmente es perturbada e intervenida por las prácticas ganaderas convencionales (Mahecha, 2002; Chará, 2003; Murgueitio, 2003; Chará et al., 2007; Ríos et al., 2007). En el caso del municipio de Matiguás (Nicaragua), una opción de este tipo puede ser económica y ecológicamente viable donde gran parte de los sistemas ganaderos son doble propósito y el manejo de árboles en los potreros es muy frecuente (Betancourt et al., 2003), abarcando gran parte de las cuencas hidrográficas de la zona, como ocurre en muchas partes del mundo (Murgueitio e Ibrahim, 2001).

Para efectos del presente estudio y específicamente para conocer la percepción comunitaria del agua y la biodiversidad, se definió el bienestar de los productores como el balance y la sinergia entre los diferentes capitales comunitarios (natural, cultural, humano, social, político, financiero y construido). De acuerdo a su función, los capitales de la comunidad pueden ser agrupados en capitales de base (capital natural, el capital humano y el cultural), y capitales de desarrollo (capital social, el capital político, el capital financiero y el capital construido). Los capitales de base forman los cimientos mediante los cuales se pueden construir otros para propiciar un cambio social profundo. Por otro lado, los capitales de desarrollo son los que mueven con mayor o menor proporción el desarrollo de las comunidades (Flora, 2004; Flora, Flora y Fey, 2004; NRFC, 2005; Emery y Flora, 2006). Se hizo énfasis en la biodiversidad y el agua como componentes centrales del capital natural.

Esta investigación utilizó metodologías participativas que permitieron conocer la percepción de los productores hacia la biodiversidad y la calidad del agua. Además, posibilitó analizar y demostrar la relación existente entre la biodiversidad y los principales usos del suelo y SSP con la calidad del agua, así como con el bienestar de los productores. Es aquí donde herramientas como el Marco de los Capitales de la Comunidad son de utilidad en la identificación de actores fronterizos claves en proyectos de reducción de la pobreza, expansión del liderazgo local, el apoyo a la autosuficiencia familiar e identificación de factores comprometidos en el bienestar de las comunidades (Flora, Flora y Fey, 2004).

\section{MATERIALES Y MÉTODO}

\section{Descripción del área de estudio}

La investigación se realizó con productores ganaderos de las comarcas Paiwitas, Las Minitas, Patastule, Las Limas y El Bijagual, en el municipio de Matiguás y la comarca San Ignacio de Paiwas en el municipio de Río Blanco, en el departamento de Matagalpa, Nicaragua. La zona presenta una topografía con un rango altitudinal entre los 224 y $500 \mathrm{~m}$ y se localiza entre las coordenadas $85^{\circ}$ y $27^{\circ}$ de latitud Norte, $12^{\circ}$ y $50^{\circ}$ de longitud Oeste. Posee un régimen de 
lluvias anuales que varía entre 1200 y $1800 \mathrm{~mm}$, con una distribución de mayo a noviembre y temperatura media anual que oscila entre 30 y $32^{\circ} \mathrm{C}$ (Ruíz, Gómez y Harvey, 2005). La zona de vida es bosque semideciduo (Meyrat, 2000) y presenta características de Bosque Húmedo Tropical (Holdridge, 1978).

El principal uso del suelo en Matiguás corresponde a la ganadería doble propósito con pastoreo extensivo (Betancourt et al., 2003). Se caracteriza por encontrarse dominado por una matriz de pasturas abiertas que cubren el $56 \%$ del municipio, con $15 \%$ de pasturas arboladas, $11 \%$ de fragmentos de bosques, $7 \%$ de charrales, $3 \%$ de corredores ribereños, $2 \%$ de cercas vivas y $6 \%$ con otros usos de suelo (Useche, 2006).

\section{Sistematización de la información secundaria}

Se efectuó una sistematización de la información provista por el proyecto "Enfoques Silvopastoriles para el Manejo Integrado de Ecosistemas" (GEF-SSP), que se ejecutó por CATIE, CIPAV y NITLAPAN-UCA en Costa Rica, Colombia y Nicaragua, respectivamente, y financiado por el GEF y el Banco Mundial. En Nicaragua, la línea base integró a 137 productores distribuidos en comarcas del municipio de Matiguás, estratificados ${ }^{4}$ en tres grupos: pequeño productor agrícola-ganadero (49\%), ganaderos medianos (39\%), productores ganaderos semi-intensivos (12\%).

También se realizó una búsqueda de información secundaria en instituciones de carácter estatal y organizaciones no gubernamentales (ONG), involucradas con la problemática ambiental y específicamente con programas o proyectos de agua en la zona de estudio, a fin de contrastar (triangular) con la información obtenida en las entrevistas semiestructuradas y los grupos focales.

\section{Identificación y selección de los productores}

De los 137 productores registrados en la línea base del proyecto GEF-SSP se tomó una muestra de 10 mujeres y 49 hombres quienes se estratificaron y renombraron en grandes (productores ganaderos semi-intensivos, $\mathrm{n}=16$ ), medianos (medianos ganaderos, $\mathrm{n}=18$ ) y pequeños (pequeño productor agrícolaganadero, $n=25)$. Para la tipología de productores grandes se tomó el $100 \%$ del grupo que corresponde en la línea base, para los grupos de productores medianos y pequeños fue el $34 \%$ y $38 \%$, respectivamente.

\section{Entrevistas semiestructuradas y grupos focales}

Con el fin de indagar y completar la información necesaria para el análisis de la problemática del agua en la zona, se realizaron entrevistas semiestructuradas y talleres con grupos focales (Madriz, 2000; Grudens-Schuck, Lundy-Allen y Larson, 2004; Larson, Grudens-Schuck y Lundy-Allen, 2004). Los protocolos para la entrevista y los grupos focales se elaboraron teniendo en cuenta qué información relevante con la investigación no estaba registrada en la base de datos proporcionada por el proyecto GEF-SSP. 
Para cada uno de los capitales se seleccionaron un número de indicadores (preguntas abiertas y específicas). En total se contó con 81 indicadores, entre los seleccionados de la base del proyecto GEF-SSP y los diseñados para esta investigación, clasificados por ejes temáticos dentro de cada capital (Tabla 1). Las instituciones ( $\mathrm{n}$ $=10$ ) relacionadas con la temática de la investigación y citadas por los productores fueron entrevistadas, para ello se elaboró un protocolo con un número de 7 a 11 indicadores. Adicionalmente, se realizaron observaciones participantes en la zona de estudio con el objetivo de corroborar parte de la información suministrada durante las entrevistas a los productores.

Tabla 1. Marco de los Capitales y ejes temáticos usados con los productores ganaderos del municipio de Matiguás, Nicaragua

\begin{tabular}{|c|c|c|}
\hline Capital & $\begin{array}{l}\text { Números de } \\
\text { indicadores }\end{array}$ & Ejes temáticos \\
\hline Natural & 17 & $\begin{array}{l}\text { Percepción de la calidad y cantidad del agua. } \\
\text { Estrategias de conservación. }\end{array}$ \\
\hline Humano & 4 & $\begin{array}{l}\text { Capacitación en manejo del agua y biodiversidad. } \\
\text { Calidad del agua y salud de la familia. }\end{array}$ \\
\hline Social & 10 & $\begin{array}{l}\text { Trabajo comunitario y calidad del agua. } \\
\text { Toma de decisiones en la finca. }\end{array}$ \\
\hline Politico & 5 & Legislación e institucionalidad. \\
\hline Financiero & 7 & $\begin{array}{l}\text { Incentivos y conservaciōn del agua. } \\
\text { Ataques ofídicos al ganado. }\end{array}$ \\
\hline Construido & 23 & $\begin{array}{l}\text { Infraestructura y tecnologías relacionadas con la } \\
\text { conservación y mejoramiento de la calidad del agua. }\end{array}$ \\
\hline Cultural & 15 & $\begin{array}{l}\text { Usos de la herpetofauna. } \\
\text { Cacería y comercialización de la herpetofauna. } \\
\text { Conocimiento de la herpetofauna. } \\
\text { Sistemas silvopastoriles. }\end{array}$ \\
\hline
\end{tabular}

Se realizaron cuatro talleres con adultos y niños empleando la metodología de Grupo Focal. Este método es una herramienta de investigación cualitativa que consiste en una reunión con modalidad de entrevista grupal abierta y estructurada (Grudens-Schuck, LundyAllen y Larson, 2004). Para ello se tuvo en cuenta lo planteado por Grudens-Schuck, Lundy-Allen y Larson (2004) y Larson, GrudensSchuck y Lundy-Allen (2004), identificando y seleccionando previamente un grupo de personas (6 a 12 individuos) con características similares (experiencia y conocimiento sobre el tema que se va a debatir).

\section{Análisis de los datos}

Las entrevistas semiestructuradas fueron tabuladas en una matriz conformada por tipo de productor (pequeño, mediano y grande) e indicadores (variables) agrupados por capital (natural, humano, social, político, cultural, físico o construido y financiero). La información adicional más relevante obtenida durante las entrevistas y en los grupos focales se agrupó por capitales en mapas mentales.

Se aplicó estadística descriptiva y tablas de frecuencia para analizar las variables obtenidas de la línea base del proyecto GEF, complementada con la información obtenida de las entrevistas semiestructuradas. Se identificaron los factores relacionados con la percepción de los tres tipos de finqueros sobre la biodiversidad y 
calidad de las fuentes de agua para consumo humano y animal y su relación con los capitales de la comunidad. Se construyeron dos índices (índice por capital e índice general) para cada uno de los productores entrevistados $(n=59)$. Los enunciados de los indicadores previamente se estandarizaron como afirmativos. El índice por capital se elaboró tomando las respuestas de los indicadores de cada capital, estas fueron llevadas al intervalo $[0,1]$ para su posterior sumatoria, el resultado corresponde al índice por capital. El índice general, consistió en la sumatoria de los índices por capital transformados al intervalo [0,1]. Los valores de los índices fueron analizados por una comparación de medias y un ANAVA de acuerdo al tipo de productor. Se utilizó para los análisis el software estadístico InfoStat/Profesional (Di-Rienzo et al. 2012). Los resultados fueron contrastados con la información adquirida de las instituciones para fundamentar la sinergia entre los capitales en relación con el capital natural.

\section{RESULTADOS Y DISCUSIÓN}

\section{Grupos de productores y capitales}

No se encontraron diferencias significativas $(p \leq 0,05)$ en la percepción de los tipos de productores (grandes, medianos y pequeños) con respecto a la relación entre biodiversidad y calidad de agua y la clase de capital. En el índice general de capitales por tipo de productor, el menor valor fue para el grupo mediano $(2,97)$ y el mayor fue para los pequeños $(3,37)$ (Figura 1). Según el índice de capitales, el capital político es percibido como de menor incidencia ${ }^{5}$, seguido del capital construido (reportes similares en las diferentes tipologías). Los capitales humano, financiero y social son los que se reportan como de mayor peso en el índice total.

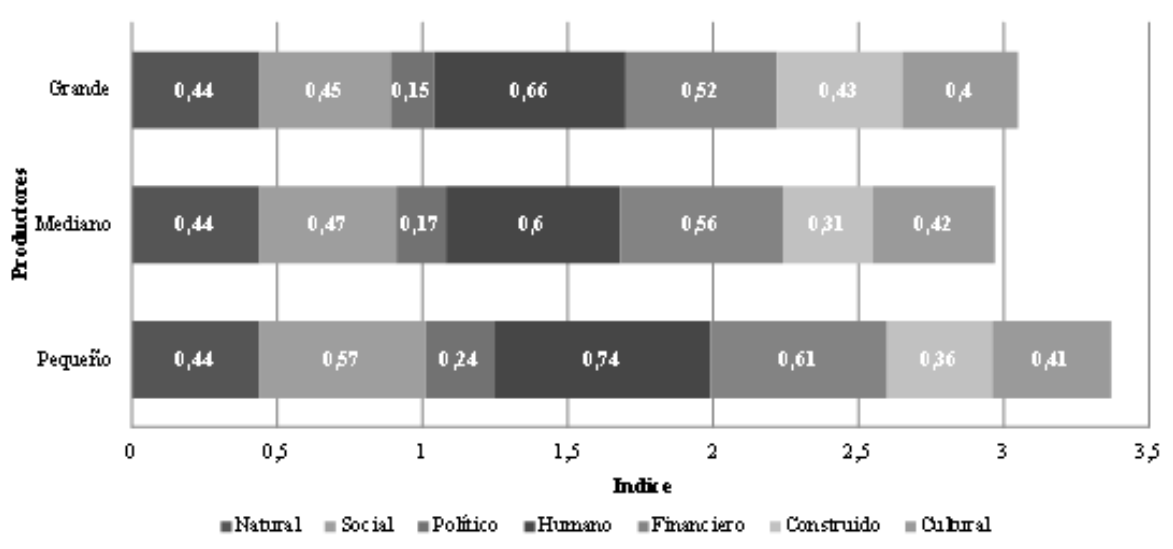

Figura 1. Aporte de cada capital al Indice General según la tipología de los productores ganaderos en el municipio de Matiguás, Nicaragua. 


\section{Capital Natural}

\section{Percepción de la calidad y cantidad del agua}

De acuerdo a lo detallado en la Tabla 2, cuatro de los 10 indicadores que conforman el tema de percepción de la calidad y cantidad del agua se relacionan con la tipología del productor (Chi Cuadrado $p \leq 0,05$ ). El $69 \%$ de los grandes productores consideran que la calidad y cantidad del agua no afecta al ganado, mientras que la mayoría de los medianos $(72 \%)$ y de los pequeños $(60 \%)$ afirman que sí hay relación entre la calidad y cantidad del agua con la salud de sus animales (Chi Cuadrado $p=0,0459$ ). Algunos productores $(24 \%)$ son conscientes de que el agua no es de buena calidad para sus animales, pero al no tener más fuentes deben hacer uso de estas y evitar gastos adicionales por el traslado del ganado en busca de agua.

Tabla 2. Indicadores que conforman el tema de percepción de la cantidad del agua del capital natural en productores ganaderos del municipio de Matiguás, Nicaragua

\begin{tabular}{|c|c|c|c|c|c|c|c|}
\hline \multirow{3}{*}{ Indicador } & \multirow{3}{*}{$\begin{array}{l}\text { Valor } \mathrm{p} \\
\text { máximo } \\
\text { verosímil }\end{array}$} & \multicolumn{6}{|c|}{ Tipología } \\
\hline & & \multicolumn{2}{|c|}{$\begin{array}{l}\text { Pequeño } \\
(\mathrm{n}=25)\end{array}$} & \multicolumn{2}{|c|}{$\begin{array}{l}\text { Mediano } \\
(\mathrm{n}=18)\end{array}$} & \multicolumn{2}{|c|}{$\begin{array}{l}\text { Grande } \\
(n=16)\end{array}$} \\
\hline & & Sí & No & Sí & No & Sí & No \\
\hline $\begin{array}{l}\text { La calidad y cantidad del agua afecta } \\
\text { al ganado. }\end{array}$ & 0,0459 & $60^{*}$ & 40 & 72 & 28 & 31 & 69 \\
\hline $\begin{array}{l}\text { La calidad del agua en la finca para } \\
\text { los animales u otras actividades es } \\
\text { buena. }{ }^{* \star}\end{array}$ & 0,1445 & 88 & 12 & 72 & 28 & 62 & 38 \\
\hline $\begin{array}{l}\text { Existe una relación entre la } \\
\text { herpetofauna con la calidad del agua. } \\
\text { Están presentes los reptiles y los }\end{array}$ & 0,2255 & 76 & 24 & 94 & 6 & 81 & 19 \\
\hline $\begin{array}{l}\text { anfibios durante todo el año. } \\
\text { La agricultura afectará la calidad o }\end{array}$ & 0,0904 & 76 & 24 & 72 & 28 & 44 & 56 \\
\hline cantidad del agua. & 0,2016 & 64 & 36 & 44 & 56 & 38 & 62 \\
\hline $\begin{array}{l}\text { La ganadería afectará la calidad o } \\
\text { cantidad del agua. }\end{array}$ & 0,4382 & 68 & 32 & 83 & 17 & 81 & 19 \\
\hline $\begin{array}{l}\text { La agricultura y ganadería han } \\
\text { afectado las fuentes de agua que } \\
\text { nacen o pasan por la finca. }{ }^{\star x}\end{array}$ & 0,0290 & 40 & 60 & 33 & 67 & 75 & 25 \\
\hline $\begin{array}{l}\text { Ha dejado de usar fuentes de agua } \\
\text { debido a la reducción de las } \\
\text { mismas.** }\end{array}$ & 0,0417 & 32 & 68 & 22 & 78 & 62 & 38 \\
\hline $\begin{array}{l}\text { El abastecimiento del agua en la } \\
\text { finca para los animales es } \\
\text { suficiente.** }\end{array}$ & 0,8381 & 60 & 40 & 61 & 39 & 69 & 31 \\
\hline $\begin{array}{l}\text { En } 5 \text { años el abastecimiento del agua } \\
\text { en la finca será suficiente. }\end{array}$ & 0,0373 & 60 & 40 & 39 & 61 & 81 & 19 \\
\hline
\end{tabular}

\section{Efectos de la ganadería y la agricultura sobre calidad de las fuentes de agua}

Con respecto a los efectos de la agricultura y la ganadería sobre las fuentes de agua, el $75 \%$ de los productores grandes creen que la agricultura y la ganadería inciden de manera negativa sobre las condiciones de las fuentes de agua que nacen y pasan por sus fincas (Chi Cuadrado $p=0,029$ ) y de estos mismos, el $81 \%$ opinan 
que la ganadería seguirá afectando la calidad o cantidad de las fuentes de agua, mientras que el $38 \%$ consideran que la agricultura será la principal causa de contaminación de las fuentes hídricas. Este comportamiento es similar en el $83 \%$ de los productores medianos quienes consideran que la ganadería perturbará las fuentes hídricas. Pocos entrevistados mencionan la falta de un buen manejo de los empaques de los productos químicos agrícolas (principalmente herbicidas), los cuales, por lo general, terminan en las fuentes de agua (observación personal).

Contrastantemente, el $60 \%$ de los pequeños productores indican que la agricultura y la ganadería no han afectado sus quebradas, aunque a futuro un gran porcentaje $(60 \%)$ afirman que estas dos prácticas productivas seguirán incidiendo en los factores de calidad y cantidad de los recursos hídricos. Referente a lo antes mencionado un productor comenta:

[...] la gente fumiga mucho con químico, usted sabe que eso viene a caer abajo al agua, aunque uno diga yo estoy largo, pero cuando llueve todo eso va para allá. Mire yo gracias a Dios yo no acostumbro a fumigar nada por eso, pero si usted mira [menciona a un vecino] como fumigó todo eso allá y todos esos venenos vienen a caer a la caña, a los ojos de agua que tiene aquí abajo, aunque nosotros digamos no porque eso va para abajo, que se queda en la tierra, pero eso de una y otra forma llegan hasta el agua. Entonces con el tiempo nosotros tenemos toda contaminada las aguas, y eso nos va a perjudicar no solo a la ganadería, sino a nosotros también (Productor mediano, hombre adulto, comarca Paiwitas).

Los entrevistados afirman como principales causas de contaminación o perturbación de los cuerpos de agua la deforestación ("despale") y el permitir beber al ganado directamente en las quebradas o ríos ("aguar el ganado"). Los productores reconocen que los animales por medio de sus heces y orina están alterando las condiciones de calidad del agua, y que en la época de verano puede ser mayor el daño, ya que el caudal de las quebradas y ríos es menor. Esta percepción puede ser corroborada con los estudios realizados por Chará (2003) y Murgueitio (2003), quienes encontraron que la falta de cobertura vegetal nativa, la ganadería de pastoreo sin árboles y el libre acceso de los animales a los cuerpos de agua generan sedimentación, y las deposiciones incrementan en gran medida los coliformes fecales y patógenos que deterioran las corrientes de agua. Contradictoriamente, algunos productores creen que al correr el agua por su cauce ("100 metros aproximadamente") estos contaminantes desaparecen por acción del golpe con las piedras y otros elementos propios del cauce de los ríos ${ }^{6}$.

Los tres grupos de productores consideran que el abastecimiento del agua en la finca es suficiente para sus animales. Aunque el $63 \%$ de los grandes productores reportan que han dejado de utilizar fuentes de agua debido a la reducción del volumen de las mismas (Chi Cuadrado $p=0,0417$ ), e insisten en que esto no afectará el 
abastecimiento en la finca. El $61 \%$ del grupo de productores medianos estiman que en cinco años el suministro del agua no será suficiente para sus actividades siendo un problema latente, las tipologías pequeño y grande opinan lo contrario (Chi Cuadrado $p=$ 0,0373). Situación similar es reportada por productores $(9 \%)$ de los cantones de Orotina, San Mateo, Esparza y Miramar en el Pacífico de Costa Rica quienes manifestaron como problema para el ganado la falta de agua durante la época seca (Fujisaka et al., 1997).

En general, los productores reconocen que existe una relación entre la herpetofauna presente en las fuentes de agua con la calidad de las mismas. Algunos productores (66\%) perciben que los reptiles y anfibios se observan durante todo el año. La época de mayor abundancia de los anfibios (ranas y sapos) según el $78 \%$ de los entrevistados es en invierno, aunque un 15\% observan que están presentes durante todo el año, el restante $7 \%$ los avistan en verano o no se han percatado. En el caso de los reptiles (lagartijas y serpientes) su distribución a lo largo del año es más homogénea, ya que el $36 \%$ de entrevistados las observan en verano, el $27 \%$ durante todo el año, el $7 \%$ en invierno y un $15 \%$ no se ha percatado al respecto.

\section{Estrategias de conservación del agua}

Los diferentes grupos de productores ganaderos en su gran mayoría (más del 92\%) protegen los nacimientos que hay en las fincas. También coinciden en afirmar que han dejado bosques o partes de bosques sin cortar porque creen que favorecen la flora y la fauna presentes en sus propiedades. Sin embargo, como expresó un productor entrevistado, una de las principales causas de no conservación del agua es la "falta de cultura o conciencia", las cuales pueden ser reforzadas por un programa o proyecto de educación ambiental:

[...] conservar el agua no es complicado, lo que pasa es falta de cultura de la conservación del agua, es más fácil deforestarla que reforestarla, por eso le digo que falta un programa para los productores y toda la gente que tiene agua, [...], lo que no hemos sabido es conservarla (Productor grande, hombre adulto, comarca Las Limas).

Con respecto a resultados obtenidos con las cercas vivas, los árboles dispersos y la regeneración natural para la permanencia de fuentes de agua en las fincas, entre el $50 \%$ y el $81 \%$ de los diferentes productores opinan que no han visto un resultado favorable. No obstante, Ríos, Andrade e Ibrahim (2008) evaluaron el impacto de las pasturas nativas sobrepastoreadas, pasturas nativas con árboles, pasturas mejoradas con árboles y un bosque secundario intervenido sobre el recurso hídrico en zonas de recarga. Dichos autores concluyeron que los sistemas silvopastoriles, al tener el componente arbóreo, mostraron mayores beneficios hidrológicos en la zona de recarga, ya que disminuyeron la escorrentía superficial e incrementaron la infiltración y favorecieron a una mayor conservación de agua en el suelo. 


\section{Capital Humano}

\section{Calidad del agua y salud de la familia}

La mayoría de los productores pequeños, medianos y grandes (92\%, 67\% y $75 \%$, respectivamente) afirman que la calidad del agua para consumo doméstico no afecta la salud de sus familias, aunque señalan que los análisis de laboratorio no han sido hechos en sus fuentes de agua. Es de resaltar que el Centro de Salud y la Alcaldía Municipal de Matiguás realizan monitoreos a los pozos de agua comunales que existen en las diferentes veredas. Durante las entrevistas de esta investigación se conoció que algunas de estas pruebas han reportado la presencia de coliformes fecales por encima de los niveles permitidos ${ }^{7}$.

\section{Capacitación en manejo del agua y herpetofauna}

El $50 \%$ de los medianos y grandes productores entrevistados afirman que han recibido capacitaciones sobre el manejo del agua o animales silvestres. El porcentaje es menor (44\%) cuando se trata de los pequeños productores. Los entrevistados señalan varias instituciones como las encargadas de trabajar en temas de capacitación y asesoramiento del agua. Ninguno de los productores entrevistados manifestó haber tomado capacitaciones específicas sobre el manejo de la herpetofauna, pese a que el $37 \%$ de los entrevistados consideran que alguna especie de reptil o anfibio ha sido problemático para sus animales o cultivos.

Varias especies son reportadas como nocivas por los productores, por ejemplo Sceloporus variablilis (lagartija) la cual corta y arranca las plántulas de maíz durante la germinación. Por su baja incidencia, estos daños no son considerados económicamente importantes; además, con prácticas culturales como el uso de la "hulera", pueden ser alejadas de los cultivos. Un solo productor reportó la aplicación de un biocida de síntesis química para contrarrestar estos ataques. El Rhinella marina es asociado según los productores con enfermedades en juveniles de aves de corral al "chupar" la cloaca. En cerdos este mismo comportamiento ocurre en la herida producto de la castración. En general, de las especies de serpientes reportadas, la mayoría son consideradas como peligrosas para los productores y el ganado.

\section{Capital Social}

\section{Trabajo comunitario y calidad del agua}

En torno a la problemática del agua, se reporta que en algunas comarcas se organizaron y gestionaron proyectos para garantizar el acceso y abastecimiento permanente del agua. Los entrevistados en su totalidad manifiestan la intención de trabajar con otras personas y consideran que esto podrá mejorar la calidad del agua en su comarca. Es así como surge el proyecto de acueducto comunal en las comarcas de Paiwitas, Paiwas y San Ignacio con una cobertura de 45 familias. Similares estrategias fueron adoptadas en las comarcas Las Limas y Patastule por los productores en la gestión 
de pozos comunales. En todos los casos, los beneficiarios de los proyectos se asocian y conforman una organización denominada Comité de Agua, la cual tiene como objetivo velar por el buen manejo, administración y uso del agua en los acueductos y pozos públicos rurales de las comarcas. Es importante resaltar que la participación en los comités de agua presentes en la zona de estudio no supera el $44 \%$ en los pequeños productores, seguido de los medianos (39\%) y grandes (38\%).

Todos los productores grandes y medianos entrevistados consideran que existen problemas de calidad y acceso en las fuentes de agua local y nacional. En menor porcentaje (88\%) los pequeños productores ratifican esta apreciación. A nivel nacional, algunos casos son producto de la explotación excesiva de los acuíferos y a la degradación progresiva de la calidad del agua por las actividades agrícolas e industriales. Esta situación es una amenaza latente para la disponibilidad futura de agua para usos vitales de la población (Castillo et al., 2006). Otros casos relacionados con la contaminación de pozos públicos por empresas (López, 2007), problemáticas por pozos clausurados (Munguía y Pérez, 2007) y la nueva Ley de Aguas (Pantoja y Córdoba, 2007) son algunos de los reportes que frecuentemente son publicados en los diarios nacionales (El Nuevo Diario, La Prensa).

\section{Toma de decisiones en la finca}

Los productores entrevistados comparten la toma de decisiones en el manejo de la finca, en mayor porcentaje los pequeños (88\%) y medianos (89\%). El $31 \%$ de los grandes productores comparten con personas distintas a su familia (mandadores o mayordomos). El más alto porcentaje de participación de las esposas en la toma de decisiones se presenta en los pequeños productores (48\%), seguido de los medianos (28\%) y en último lugar están los grandes (13\%) (Chi cuadrado $p=0,0449$ ). Es de notar que a nivel familiar este último grupo tiene un poco más de preferencia por los hijos en cuanto a la toma de decisiones.

\section{Capital Político}

\section{Legislación e institucionalidad}

En su totalidad los productores entrevistados consideran que necesitan al gobierno o alguna ONG para proteger y mejorar la calidad del agua. El marco institucional reportado por los productores entrevistados está conformado por 17 entidades gubernamentales y no gubernamentales involucradas en la problemática del agua y la biodiversidad. Las instituciones frecuentemente mencionadas son Nitlapan-UCA (38\%), ENACAL $(14 \%)$, SANEBAR (11\%), Agua para la Vida $(11 \%)$ y FONDEAGRO $(6 \%)$, el $20 \%$ restante está conformado por instituciones varias (Alcaldía Municipal de Matiguás, TROPITECNIA, INTA, MARENA, FONDESER, Centro de Salud San José, Iglesia de Matiguás, MINSA, Cruz Roja, MAGFOR, PROCAMPO, FUDEMAG). Durante las entrevistas, el $37 \%$ de los productores al menos reconocen una institución, un porcentaje cercano $(34 \%)$ no identifican a ninguna entidad. El $14 \%, 12 \%$ y $3 \%$ de los productores (pequeños, medianos 
y grandes, respectivamente) reconocen dos, tres o cuatro instituciones. Además, citan principalmente como posibles ayudas por parte de estas entidades la adecuación y construcción de pozos y pilas, análisis de calidad de las fuentes de agua para consumo humano y animal, facilitación de materiales relacionados con el transporte de agua, capacitación y asistencia técnica.

El $90 \%$ de los productores afirman que es necesario la implementación de más leyes que regulen la protección y manejo de los recursos naturales (agua y biodiversidad). Algunos de los factores mencionados por los entrevistados son: falta de conocimiento y aplicación de la legislación (incluyendo la poca presencia de la Policía Nacional o la Alcaldía Municipal), falta de conciencia y educación de los productores.

El Consejo Municipal del municipio de Matiguás emanó como medida de control para mitigar los diferentes casos de abuso contra la fauna y flora, la Norma de Regulación y Control en el Manejo y Uso de los Recursos Naturales y del Ambiente (Alcaldía Municipal de Matiguás, 2003). Esta norma no es conocida en la comunidad e incumplida por algunos de los habitantes. Según entrevista realizada a la Policía Nacional (Municipio de Matiguás) en los ocho primeros meses de 2007 se realizaron seis operativos para controlar el transporte de leña. Ningún operativo fue realizado para controlar el vertimiento de aguas residuales en los ríos o quebradas, lavado de vehículos ${ }^{9}$ o recipientes para el transporte de productos lácteos o caza y comercialización de animales como Iguana iguana y Ctenosaura similis vedados por el MARENA.

\section{Capital Financiero}

\section{Incentivos y conservación del agua}

Las tipologías pequeño y grande reconocen en su totalidad que es importante ofrecer un tipo de incentivo y destinar más recursos públicos que favorezcan la conservación y mejoramiento de la calidad y acceso del agua. En un menor porcentaje (94\%) los productores medianos consideran favorable estas medidas. Entre los incentivos mencionados por los productores están la construcción de pozos artesianos ${ }^{10}$, la provisión de materiales para el mejoramiento y adecuación de los pozos artesanales y pilas (tanques de almacenamiento de agua), materiales para el transporte de agua y aislamiento de las nacientes, análisis de la calidad del agua, entre otros (Figura 2). 


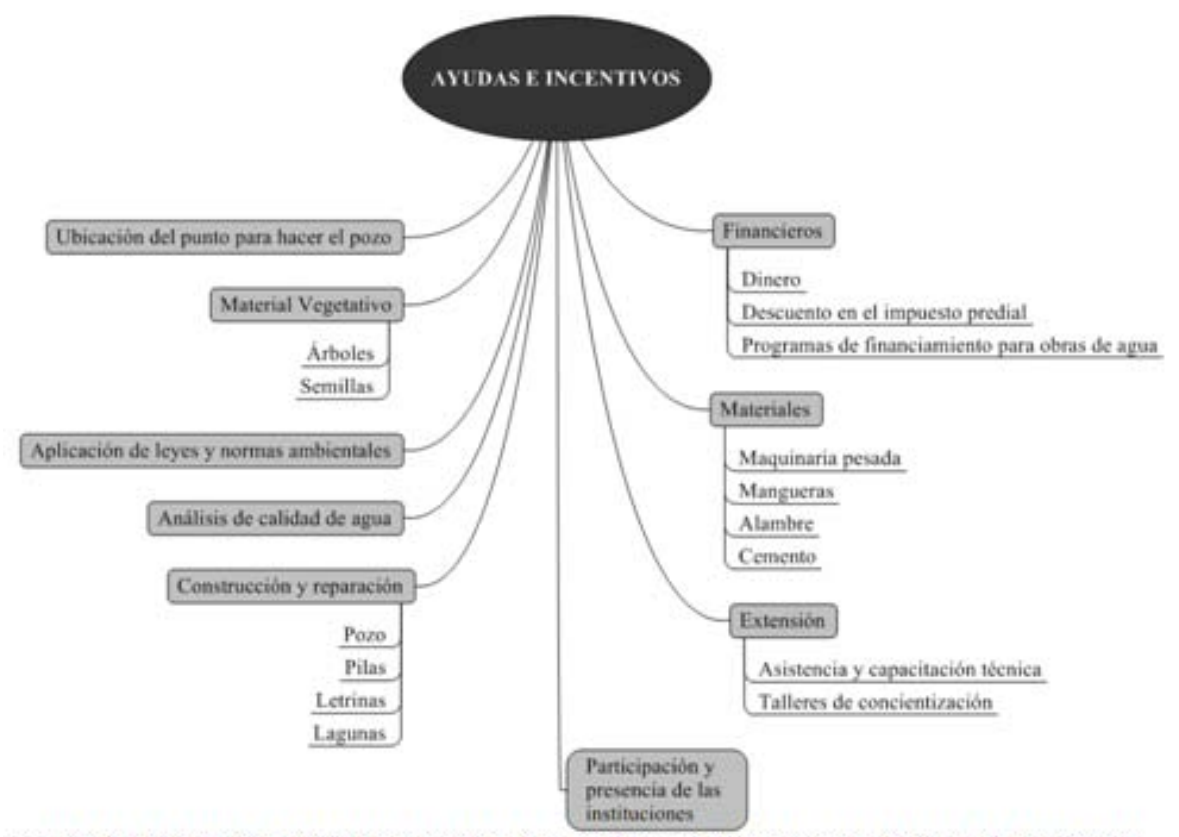

Figura 2. Incentivos y ayudas mencionadas por los productores ganaderos del municipio de Matiguás que podrían ser brindados por las instituciones o proyectos para la conservación, cuidadoy mejoramiento de las fuentes de agua para consumo humano y animal.

Algunos productores afirman que hay una ausencia de instituciones financieras que otorgan créditos, préstamos o incentivos monetarios para la construcción de obras de almacenaje, conducción o abastecimiento del agua en las fincas. Esta información fue corroborada con las instituciones que ofrecen paquetes financieros en el Municipio. No obstante, algunos productores logran financiamiento para estas obras, utilizando ante las financieras figuras distintas de inversión del dinero a las aprobadas.

Sí, tome un crédito para hacer el pozo [...] no dije que era para hacer el pozo, porque no me lo daban, sí me dan para vacas, para ganado pues, pero para pozo no, para construcciones no. Yo dije voy a comprar dos vacas, bueno entonces tomé 1895 dólares ${ }^{11}$ [se refiere a la respuesta de la financiera], me fueron a ver las vacas, entonces yo di las mías e invertí el dinero en el pozo (Productora mediana, mujer adulta, comarca Patastule).

Otro factor importante es que el $100 \%$ de los entrevistados opinan que mejorar la calidad y cantidad de las fuentes hídricas de consumo humano y animal presentes en las fincas valorizará las propiedades. Consideran igualmente que la madera y las vías de acceso que estén en la finca también influirán sobre el valor de la propiedad. También recomiendan la época ideal para comprar una finca en verano, otros afirman que muchas fincas dependen de la época (invierno y verano) para su óptima producción. Un productor entrevistado opina al respecto:

[...] en verano, para saber si tiene agua, ver cómo es el pasto, porque en el verano todo se escasea. [...] hay otras que solo son 
fincas veraneras, porque en el verano llueve menos, hay agua y pastos, hay otras que solo son de invierno, que solo en el invierno hay agua y hay comida, hay otras que sirven en las dos épocas, tienen agua en el invierno y en el verano, no son frías, no tienen demasiada precipitación de agua y no son muy fangosas, pueden andar en el invierno y en el verano los animales, esa es la finca cara, porque sirven en las dos épocas (Productor grande, hombre adulto, comarca Las Limas).

Igualmente, la mayoría de los productores $(75 \%$ al $80 \%)$ piensan que si cambian las pasturas naturales a pasturas mejoradas podrán obtener un mayor beneficio para la finca y la familia. Además, creen que adquirir más tierras o colocar riego no ayudará a mejorar la situación económica del hogar.

\section{Inversión y gastos relacionados con disponibilidad de agua}

Muy pocos de los entrevistados dijeron cuánto dinero gastan e invierten al año para tener agua para uso humano y animal en las fincas. Los gastos estimados varían de acuerdo a la actividad realizada que van desde 52 dólares hasta 2700 dólares, pero la gran mayoría son conscientes de que realizan una inversión para lograr el acceso al agua.

Para la construcción de un pozo los productores invierten de 217 a 1283 dólares $^{12}$, este costo depende de factores como la profundidad de cavado, dureza del suelo, revestimiento de las paredes, brocado y tipo de bomba. Según lo narrado por un "pocero" entrevistado, la localización del sitio de perforación (dos posibles puntos) vale 54 dólares, cavar una vara cuesta 5 dólares y el brocal o revestimiento final vale 108 dólares. Sin embargo, algunos productores mencionaron que otro pocero cobra 11 dólares por ubicar el punto, en algunos casos por amistad esta misma persona no cobra por sus servicios. En algunas fincas la cavada del pozo la realiza el padre en compañía de sus hijos.

Las personas que tienen acueducto pagan una mensualidad por este servicio de 0,54 dólar, el dinero recaudado es manejado por el Comité de Agua quien decide su inversión, principalmente es para reparaciones en las tuberías. En el caso de los pozos comunales la tarifa mensual es determinada por el Comité de Agua, en promedio es de 1 dólar mensual, el cual va a un fondo común que es administrado por el Comité. El dinero recaudado es utilizado en las reparaciones necesarias del área comunal del pozo. Otros gastos incurridos por algunos de los productores son: adecuación de pilas o albercas, compra de pichingas o barriles, transporte de agua y reforestación de las fuentes de agua.

\section{Accidentes ofídicos}

Los accidentes ofídicos se dan principalmente en ganado, algunos en equinos y unos pocos en gallinas. El mayor porcentaje (63\%) de ataques ofídicos en las fincas se presentan en el grupo de grandes productores, seguido de los medianos (33\%) y por último los pequeños (24\%) (Chi Cuadrado $p=0,0429$ ). Esta distribución en el ataque puede relacionarse con el hecho de que los grandes 
productores cuentan con más cabezas de ganado por unidad de área que los otros grupos, aumentando la probabilidad de que un evento de esta naturaleza ocurra. Al respecto, la bibliografía consultada reporta que en sistemas de producción de doble propósito en la región central del Pacífico (Costa Rica) el $5 \%$ de productores entrevistados $(n=44)$ citan a las serpientes como problema para el ganado (Fujisaka et al., 1997).

La especie Bothrops asper conocida localmente como Barba Amarilla es la más citada durante los talleres con grupos focales en ataques ofídicos, seguida de Lachesis stenophrys (Matabuey). Esta última serpiente no se reportó en los muestreos realizados en fincas ganaderas del municipio de Matiguás (Gómez-Martínez et al., 2011), los registros más cercanos para la zona son en el municipio de Chontales (Köhler, 2001). Además, Solórzano (2004) y Köhler (2003) describen que L. stenophrys se relaciona estrechamente con la selva húmeda inalterada o bosque lluvioso primario, haciéndola muy vulnerable debido a la acelerada destrucción de la cobertura natural. Esto posiblemente indica que es otra especie la responsable de los accidentes en las fincas ganaderas del municipio de Matiguás, como la serpiente Xenodon rabdocephalus conocida como la falsa terciopelo.

Como síntoma del ataque ofídico en el ganado, los entrevistados señalan que se presenta inflación y secreciones de la zona afectada por acción del veneno, esto coincide con lo reportado por varios autores quienes consideran que el veneno está constituido por más de 50 sustancias, entre ellas la histamina, la serotonina y otros péptidos, que son los responsables de provocar la actividad inflamatoria, acciones vasomotoras y la producción de dolor durante el envenenamiento (INS, 2000; Rodríguez-Acosta, 2001; CastrillónEstrada, Acosta-Vélez y Hernández-Ruiz, 2007). En otros casos los entrevistados reportan la Boa constrictor principalmente como la causante de ataques a aves de corral.

La información suministrada por el personal médico del Centro de Salud San José de Matiguás relacionada con accidentes ofídicos fue: nueve casos registrados en el 2006, de los cuales un solo caso fue por mordida de serpiente venenosa (no identificada). Para el 2007 (enero hasta agosto) se reportaron tres casos, ninguno por serpiente venenosa. Más de la mitad de los ataques ofídicos reportados en estos años se presentaron en menores de edad (1 a 17 años). Cuatro de los pacientes realizaban actividades agrícolas y de lavandería en los ríos al momento de la mordedura por serpiente. Según lo reportado por el Centro de Salud se cree que son más los casos de este tipo, pero debido a diversos factores, principalmente el cultural, los afectados no buscan tratamiento médico especializado, sino que acuden a prácticas de medicina tradicional como los curanderos. Este tipo de tratamiento es muy practicado también en el ganado. 


\section{Capital Cultural}

\section{Usos de la herpetofauna}

Un $28 \%$ de los pequeños y medianos productores utilizan algún reptil o anfibio como medicinal, y en menor porcentaje los grandes productores emplean estos animales (6\%). Dentro de los usos más frecuentes de la herpetofauna como medicinal, se menciona la utilización de sapos (Incilius coccifer) como posible remedio o cura para la erisipela ${ }^{13}$. Los productores reportan que los usan de la siguiente manera:

[...] uno lo agarra y se lo pasa en ayunas en todo aquello que le da uno, se pasa varias veces ahí, el sapito mire se pone más lleno de borroñitas como él, se sopla se revienta y se muere y uno se cura de eso [...] es cierto porque yo lo probé en una nietecita que sufrió de eso (Productor pequeño, mujer adulta, comarca San Ignacio).

Para otras afecciones de la piel, se reporta el empleo de lagartijas:

[...] la lagartija si, la hemos utilizado, o sea que yo la he utilizado, no sé si los demás la han utilizado, pero yo la he utilizado, hay una enfermedad que le sale debajo del pie, a una, que le dicen ojo de pescado, es como una ampollita pero es dura, se siente como una estaquita para dentro, entonces ese animalito lo hemos utilizado agarrándolo y pasándose así sobre él en forma de cruz, pasándola así para allá, aquí para allá [hace la seña de la cruz en su pie], es la lagartija de paredes, una que es amarillita brillanta, y se sana porque yo padecía de eso, porque me lastimaba algo y tá! como que me hincaba, y se quita, porque a mí me la dieron de remedio [...] (Productor pequeño, mujer adulta, San Ignacio).

Aceites extraídos de serpientes (B. constrictor) e iguanas (Iguana iguana) son utilizados en los dolores de las articulaciones, "huesos" y otras afecciones reumáticas, hematomas por golpes en humanos y animales e inflamación de la ubre en el ganado. La forma reportada en las entrevistas y talleres es la siguiente:

[...] entonces una lo mata en la mañana un ejemplo y se cuelga, y ya hasta en la tarde el aceite está abajo de viaje, entonces ese tuco [trozo o parte] de ahí se echa a freír y de ahí sale el aceite de la boa (Productor pequeño, hombre adulto,comarca Las Limas).

Otros productores reportan usar las boas como controladores biológicos de ratas y otros roedores, como lo cita un mediano productor de la comarca Paiwitas: 
[...] he dejado cuatro bobas en la caña para que me controlen los ratones y ahora no tengo problemas. Una boba la llevé a la frijolera. [...] en la casa se alborotó una ratonera, entonces agarre una [boa] y la traje para acá, la metimos debajo de una cama y se comió toditos los ratones [...].

Usos similares en la cura de la erisipela durante la época hispanomusulmana o andalusí (siglo IX al XII) en España son reportados por Casal y Casal (2004), los escritos narran un tratamiento para las "placas de erisipela" que consistía en aplicar un sapo vivo abierto en canal en la zona afectada, este remedio según la lógica de los autores ya está en desuso. Reportes similares en Panamá son hechos por Garay (1932) quien cita los efectos del vientre frío del sapo que se frota contra las partes afectadas por la erisipela. Otros usos de los bufos son citados por Durán (2006) y Ramírez (2006).

\section{Cacería y comercialización de la herpetofauna}

Del $49 \%$ de los productores que consumen reptiles o anfibios, la especie más utilizada es la iguana (Iguana iguana) y el garrobo (Ctenosaura similis). Dos casos fueron reportados de consumo de ranas (especies no identificadas) y serpientes (Boa constrictor). La cacería de animales silvestres la practican del $8 \%$ al $13 \%$ de los productores, reportándose un mayor hábito dentro de la tipología grande. Es de anotar que algunos productores asocian la disminución o ausencia de las iguanas y garrobos en las comarcas con la cacería indiscriminada por parte de los habitantes de estas zonas y no con la disminución de las fuentes de agua.

Las razones principales de consumo de la carne de iguana y el garrobo reportadas por los productores, es su alto contenido nutricional ("de mucho alimento") y su buen sabor ("es rica"). El consumo de los huevos de la iguana fue mencionado pocas veces. Gutiérrez (1996) encontró que los habitantes de la región de Cosigüina (Nicaragua) atribuyen a la carne de garrobo propiedades medicinales y que los hombres de la comunidad insisten en afirmar que el consumo de este animal es reconstituyente y con propiedades afrodisiacas.

Los entrevistados reportan que la mayor presión de caza para estos reptiles es en los meses de abril y mayo, incrementándose en la época de Semana Santa y coincidiendo con el periodo de veda establecido por el MARENA que se aplica desde el 1 de enero al 30 de abril de cada año (MARENA, 2004). El aumento del consumo de estos animales en Matiguás obedece a la costumbre tradicional nicaragüense de preparar carne de garrobo e iguana en la época de cuaresma, al servir de reemplazo de otras carnes, lo cual coincide con lo reportado para la región Pacífica del país (Gutiérrez, 1996). Otro punto relacionado con la caza y comercialización de fauna, es la adopción de mascotas, muy frecuente en los medianos productores con un $44 \%$, los grupos restantes se encuentran entre el $20 \%$ y $13 \%$. La compra de animales silvestres no supera el $12 \%$ de los entrevistados. 


\section{Conocimiento de la herpetofauna}

Los nombres comunes utilizados por los productores para identificar a las especies de reptiles y anfibios fueron aprendidos en su mayoría $(93 \%)$ de sus padres. Sin embargo se encontró que dentro de la clase Reptilia, las especies del orden Serpentes son identificadas por los productores con más nombres que las especies del orden Sauria; en este último es muy generalizado el uso de los nombres gallego, cherepo y lagartija. En la clase Amphibia, las especies que conforman el orden Anura, los sapos (género Bufo) tienen nombres comunes locales, lo contrario ocurre con las ranas, las cuales son denominadas de acuerdo a su coloración o hábitos ecológicos. Los nombres comunes fueron mencionados por los productores durante los talleres con grupos focales, después de su identificación por medio de láminas fotográficas de las especias más abundantes reportadas para la zona. En general el $82 \%$ de los productores diferencian una rana de un sapo, en cambio el porcentaje disminuye cuando tienen que reconocer una serpiente venenosa de una no venenosa.

Un estudio etnozoológico realizado por Sánchez (2006) en la Reserva de la Biosfera Mariposa Monarca en México, encontró que varios de los nombres asignados a las diferentes especies tienen correspondencia a su morfología o etología. Por ejemplo, el nombre mangua de las ranas, que significa "patas largas", hace referencia a las extremidades posteriores del anuro. Similares denominaciones tienen las serpientes como la cascabel (Crotalus triseriatus), que recibe el nombre de Kihmi-poseé, que en mazahua se refiere a las manchas que cubren su piel.

Es de anotar que un gran número de productores desconocen los beneficios 0 el papel ecológico que puede desempeñar la herpetofauna en los sistemas productivos -controladores biológicos, polinización y dispersión de semillas (Galindo-Uribe y Hoyos-Hoyos, 2007) - y fuentes de agua (indicadores biológicos). Por lo anterior, demandan capacitaciones sobre el manejo de anfibios y reptiles, principalmente el reconocimiento y manipulación de serpientes. Otros productores afirman que las ranas y sapos por su coloración oscura y la textura de la piel (presencia de glándulas pronunciadas en las especies de la familia Bufonidae) son indicadores de suciedad o simplemente son rechazados por su estética.

\section{Creencias populares sobre la herpetofauna}

La sabiduría campesina transmitida de generación en generación por medios orales y de experiencia juega un papel importante en el reconocimiento y uso de la biodiversidad, ya que es adquirida del medio ambiente mediante sistemas particulares de cognición y percepción (Altieri, 1991). Además, se basa en un proceso histórico de acumulación y transmisión de conocimientos que se incrementa con la experiencia del propio productor, adquirida durante la repetición del ciclo productivo y su cultura que resultan útiles para manejar los ecosistemas (Ocampo y Escobedo, 2006).

En el conocimiento local de los productores, algunas especies de reptiles y anfibios son consideradas peligrosas por presentar 
comportamientos que ponen en riesgo la integridad física de pobladores de la zona y sus animales (Figura 3 ). Repetidamente los productores señalaron la serpiente "boba" (Boa constrictor): la "mordedura puede ser letal debido a la presencia de veneno en ciertas horas" (a la madrugada y cuando inicia la noche). Apreciación errónea debido a que esta especie de serpiente presenta una dentición de tipo aglifa (Solórzano, 2004).

Insistentemente durante los talleres con grupos focales la gran mayoría de los productores afirmaron que las serpientes Erythrolamprus mimus, Pliocercus euryzonus, Oxyrhopus petolarius, Lampropeltis triangulum y Micrurus nigrocinctus, conocidas localmente como corales, son venenosas, además hicieron énfasis en que estos colubridae pican o hincan con la cola, debido a un aguijón presente en esta parte de su cuerpo el cual puede causar la muerte en humanos. En el caso de la mordedura, de las especies reportadas como corales falsas, solo $M$. nigrocinctus es letal por su veneno neurotóxico (Savage, 2002). Es importante indicar que $O$. petolarius, E. mimus y $P$. euryzonus presentan veneno moderadamente tóxico utilizado para inmovilizar las presas, y la mordedura en humanos (en los dos últimos casos) puede causar dolor local, inflamación y hematomas moderados (Solórzano, 2004).

Otra creencia muy común entre los productores es con la serpiente mica (Spilotes pullatus), descrita como "un animal de mucha fuerza en su cola". Además citan que esta parte del cuerpo es utilizada en forma de látigo para defenderse. Algunos productores cuentan historias sobre este colubridae que es empleado en el entrenamiento de algunos productores para desarrollar destrezas y habilidades con el machete. Algunas de las apreciaciones anteriores son típicas de la etología de la S. pullatus. Al respecto, Solórzano (2004) describe esta especie como una serpiente activa en la búsqueda de sus presas, con movimientos ágiles y rápidos, de hábitos terrestres y arborícolas. Presenta como medida defensiva disposición a morder, levantando generalmente la cabeza e inflando el tercio anterior del cuerpo, mientras vibra fuertemente la cola contra el suelo. Sin embargo, es equivocado creer que la mordedura de $S$. pullatus puede causar la muerte, el veneno es ausente en su dentición (Savage, 2002; Solórzano, 2004). 


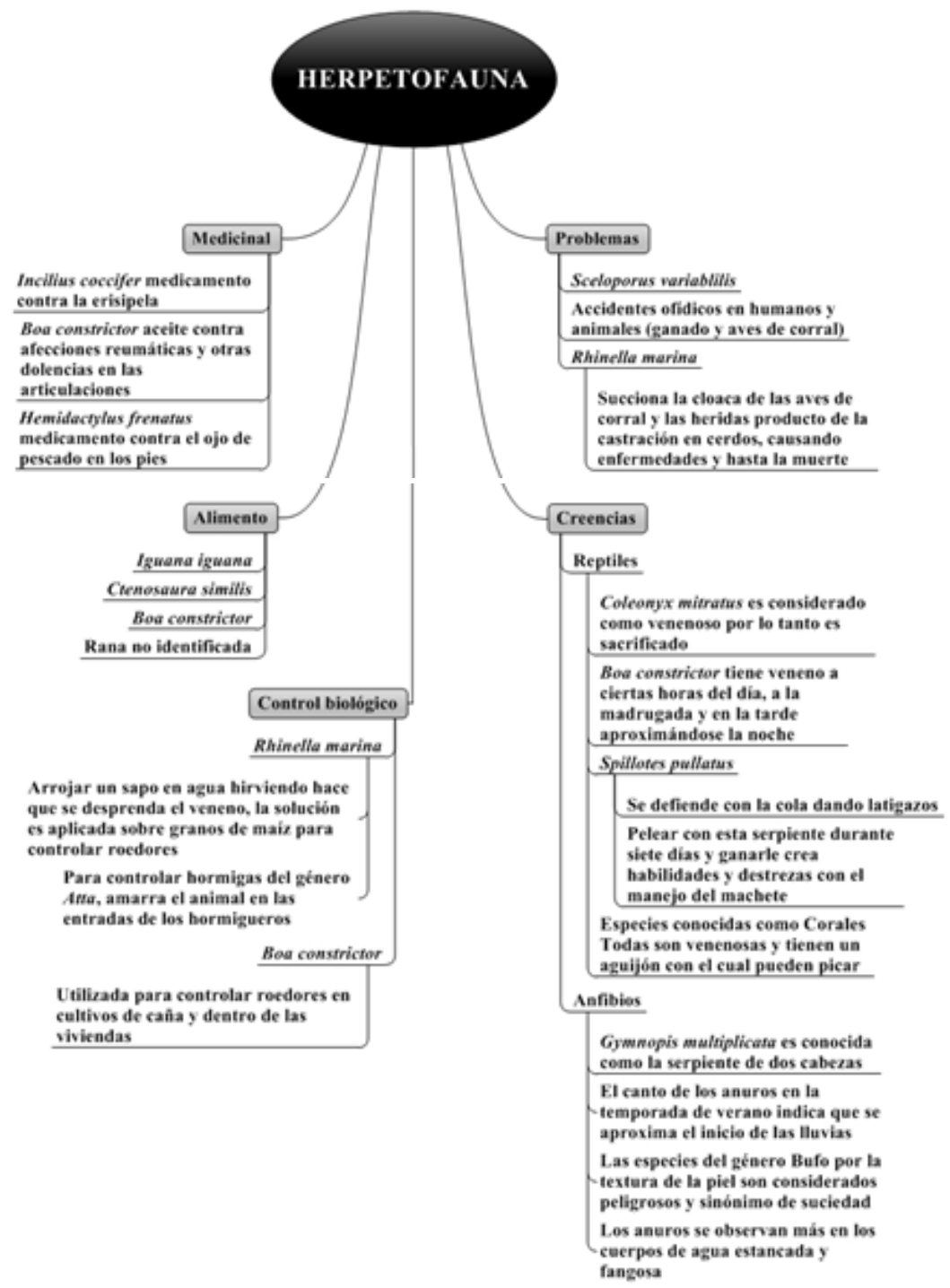

Figura 3. Usos y creencias de la herpetofauna por productores ganaderos del municipio de Matiguás, Nicaragua.

\section{Localización de agua a través de la técnica del "posero"}

En repetidas ocasiones la técnica de vareo es muy utilizada por los productores en la búsqueda de agua del subsuelo para la construcción de pozos ("pozos cobados"). Según reportes de los entrevistados, esta práctica aumentó durante los últimos años en las comarcas Patastule y Las Limas debido a la creciente necesidad de construcción de fuentes de agua alternas para consumo animal y humano. La técnica del vareo es realizada por pocas personas denominados "poceros"14, quienes utilizan un alambre o alambrón de cobre no superior a un metro de largo y en forma de U. Estas personas argumentan que "es un don que Dios les dio", en el caso del "pocero" entrevistado, comentó que ninguno de sus hijos puede realizar esta práctica.

Antes de iniciar el recorrido para localizar el punto exacto donde se debe comenzar la perforación, los "poseros" tienen en cuenta posibles sitios que fueron seleccionados tomando criterios como: 
fácil acceso, cercanía a la casa, proximidad a los bebederos o galeras, presencia de rocas, tipo de vegetación circundante y lugar seleccionado por el dueño. La búsqueda se realiza mientras se toma con las manos los extremos del alambre y conservando la forma de U. Cuando se encuentra un punto ideal (agua en el subsuelo) el alambre empieza a tener ondulaciones o movimientos bruscos, en algunos casos se retuerce o se rompe. La intensidad de las vibraciones en las manos determina la profundidad a la que se debe cavar para encontrar el agua y la cantidad de la misma.

Estudios realizados a un grupo de campesinos en la región de Atlixco, Puebla (México) mostraron resultados similares en cuanto a la técnica de localización de agua para la construcción de pozos. Personas denominadas "vareros" utilizan trozos de madera de forma lineal y en estado verde de cuatro especies vegetales reportadas para tal fin, en algunos casos emplean trozos de alambre de cobre. Conocer el ancho de la corriente es importante, porque a partir de este dato es la recomendación que el "varero" hace al solicitante (Ocampo y Escobedo, 2006).

\section{Capital Construido}

\section{Infraestructura y tecnologías relacionadas con la conservación y mejoramiento de la calidad del agua}

La percepción del $97 \%$ de los productores es que los sistemas silvopastoriles tienen una relación positiva con la calidad del agua y el número de reptiles y anfibios presentes en las fincas. Algunos argumentan que desde que dejaron árboles dispersos en los potreros o han colocado cercas vivas, estas prácticas ayudaron a proteger a los animales, además ven que las fuentes de agua en sus propiedades han sostenido su caudal durante más tiempo en la época de verano. Situación similar es reportada por Cerdán et ál. (2012), quienes encontraron que los productores conocen aspectos de la regulación del microclima por parte de los árboles en sistemas agroforestales de café en Centroamérica.

Acerca de si ha mejorado la calidad y la cantidad de agua en la finca con la implementación de sistemas silvopastoriles y si estos favorecen a la herpetofauna, un productor afirma:

[...] sí, la cantidad de agua y la calidad de pasto pues, porque ahora tengo mucho pasto de corte y mantengo más ganado, hay más leche, por lo menos antes sacaba menos leche en este tiempo, ahora saco más y que debía ser lo contrario, pues me he preparado para estos tiempos con el agua, con la comida y no tengo problema en el verano, no tengo problema (Productor grande, hombre mayor, comarca Las Limas).

Estudios realizados en Nicaragua y Costa Rica demostraron que la sustitución de pasturas nativas por mejoradas ayudan a disminuir la escorrentía y aumentar la infiltración (pasturas arboladas), resultados similares pueden ser vistos con los bancos forrajeros (gramíneas y leñosas) que debido a la alta densidad y a la elevada 
cobertura del suelo disminuyen el impacto de las gotas de agua sobre el suelo y la velocidad de la escorrentía (Ríos et al., 2007). Es de resaltar que un solo productor de los entrevistados $(n=59)$ aseguró que el nivel de su fuente de agua (quebrada) aumentó cuando él taló los arboles grandes de la rivera de la quebrada. Un comportamiento similar fue reportado en Villa Mills, Costa Rica, donde según las investigaciones ejecutadas en bosque nuboso natural con extracción del 20 o $30 \%$ del área basal de troncos recuperó fuentes de agua de aproximadamente $9300 \mathrm{~m}^{3} \mathrm{ha}^{-1}$ y $10500 \mathrm{~m}^{3} \mathrm{ha}^{-1}$ respectivamente, un volumen $\left(7600 \mathrm{~m}^{3} \mathrm{ha}^{-1}\right)$ mayor de captación que el bosque sin explotación (Turcios, 1995).

Los nacimientos de agua son cercados por la mitad de los grandes productores y un $32 \%$ y $39 \%$ por los pequeños y medianos, respectivamente. De las prácticas realizadas por estos productores para proteger sus nacimientos, se encuentra una relación entre el cercado y la siembra de árboles y arbustos con el tipo de productor (Chi cuadrado $p=0,0016$ ) siendo más frecuente en la tipología grande (44\%), seguido de los pequeños (16\%) y en ninguno de los casos los productores medianos realizan estas prácticas en conjunto, ya que la mitad de ellos siembran árboles sin cercar la naciente. El $42 \%$ de los productores efectúan otras prácticas para proteger sus nacientes de agua.

La protección de fuentes agua como riachuelos, quebradas, o ríos que cruzan por las fincas es realizada por la totalidad de los pequeños productores y por la mayoría $(94 \%)$ de los medianos y grandes. Según los tres tipos de productores, las actividades más frecuentes para la protección de estos cuerpos de agua son la regeneración natural (92\%) y la siembra de árboles y arbustos (36\%). En menor porcentaje (3\%), se citan actividades como evitar que lleguen las aguas residuales a los cuerpos de agua e instalar bebederos en los potreros. No obstante, es importante resaltar que ninguno de los pequeños y medianos productores evita el acceso del ganado a las quebradas o ríos que pasan por su propiedad, y solo el $13 \%$ de la tipología grande realizan esta actividad. Más aún se señala que los productores deben garantizar el acceso del ganado a las fuentes de agua durante las jornadas de pastoreo haciendo puntos de bebederos sobre las quebradas o ríos ("aguaderos").

En relación con la infraestructura presente en las fincas, se observa una concordancia con las tipologías de los productores (Chi cuadrado $p \leq 0,005)$. El almacenamiento del agua es realizado en menor grado por los productores pequeños $(12 \%)$ y grandes $(6 \%)$ y ausente en los medianos. Los productores pequeños reportan más letrinas $(92 \%$, Chi Cuadrado $p=0,0262)$ y agua por tubería dentro de las casas $(48 \%$, Chi Cuadrado $p=0,01)$ que los productores medianos y grandes. Específicamente para los grandes productores es muy poca la utilización de tubería para llevar el agua hasta sus casas $(6 \%)$, esto posiblemente se debe a la alta existencia $(93 \%$, Chi Cuadrado $p=0,0002$ ) de pozos en sus fincas; los productores pequeños son los que menos tienen pozos y repetidas veces se menciona dentro de las entrevistas su interés por construir o mejorar los presentes. Se encontró en algunos sitios que los productores tienen pozos propios en las fincas, esto reduce el uso de las construcciones comunales. 


\section{CONCLUSIONES}

El bienestar de los productores ganaderos se ve afectado por la calidad y cantidad del agua presente en las fincas. La salud del finquero y sus animales puede verse afectada por la calidad y cantidad del agua. Cuando el agua es abundante y permanente durante todo el año, el bienestar de los productores es menos vulnerable. En el caso contrario, los productores deben realizar labores o gastos adicionales para suplir su necesidad del agua.

Los productores ganaderos del municipio de Matiguás reconocen que la problemática existente en torno al agua a nivel local, regional y nacional está fuertemente relacionada con las prácticas agrícolas y pecuarias. Además, identifican los principales contaminantes de las fuentes de agua. Puntualmente en la finca perciben que la aplicación de químicos, la deforestación ("despale") y el ingreso del ganado a las quebradas o ríos causan contaminación y deterioro en las fuentes de agua. Otros contaminantes son el lavado de vehículos (mayor proporción camiones transportadores de leche y ganado) y de recipientes utilizados en el transporte de leche, así como las aguas residuales de las queseras de la zona.

La percepción de los diferentes grupos de productores (grandes, medianos y pequeños) en el municipio de Matiguás con respecto a la relación entre biodiversidad y calidad de agua y sus capitales (social, humano, político, natural, físico, financiero y cultural) en fincas ganaderas es muy similar. Esto favorece la toma de decisiones, elaboración y ejecución de proyectos o programas en la zona de estudio ya que no sería necesario la estratificación o diseño de propuestas distintas para cada grupo.

De la herpetofauna reportada para el municipio de Matiguás y relacionada con las fuentes de agua, algunas especies de reptiles y anfibios tienen un significado e importancia para la comunidad, ya sea como fuente de alimento, controladores biológicos, tratamientos de enfermedades o indicadores del clima (inicio de la temporada de lluvias). Entre los anfibios se reporta el uso medicinal de Incilius coccifer en el tratamiento de la erisipela y en los reptiles Hemidactylus frenatus (lagartija) es empleada para el mal de ojo de pescado y el aceite de Boa constrictor en las afecciones reumáticas. En la gastronomía tradicional la Iguana iguana y Ctenosaura similis son las principales especies utilizadas en la dieta durante la época de cuaresma. Otros casos (Boa constrictor) se registraron como controladores biológicos de roedores e insectos.

Los productores reconocen que hace falta una mejor implementación y aplicación de las leyes por las autoridades o entidades encargadas del área ambiental del municipio de Matiguás, así como programas de concientización y educación sobre la problemática del agua y los recursos naturales producto de las actividades pecuarias y ganaderas. Esto ocasiona un debilitamiento en las relaciones entre las instituciones y los productores (capital político) al no sentirse protegidos, respaldados y apoyados por las organizaciones. 


\section{AGRADECIMIENTOS}

El financiamiento para la investigación mencionada en este artículo viene del World Bank-Bank Netherlands Partnership Program para el proyecto "The Impact of Improved Cattle Management Practices on Biodiversity Conservation". Damos las gracias a los productores ganaderos de Paiwas, Paiwitas, Las Limas, Patastule y San Ignacio quienes nos permitieron trabajar en sus fincas y nos dieron parte de su tiempo y vivencias al momento de las entrevistas.

\section{REFERENCIAS}

- Alcaldía Municipal de Matiguás. (2003). Norma de Regulación y Control en el Manejo y Uso de los Recursos Naturales y del Ambiente. La Gaceta, 15-05-03, 2409-2414.

- Altieri, M.A. (1991). ¿Por qué estudiar la agricultura tradicional? Revista Agroecología y desarrollo, 1(1), 16-24.

- BCN (Banco Central de Nicaragua). (2007). Tipo de cambio oficial. $\begin{array}{llllll}\text { Recuperado el } & 10 & \text { de julio } 2007 & \text { de }\end{array}$ http://www.bcn.gob.ni/estadisticas/tasas/cambio/avisojulio07.ht m

- Betancourt, K., Ibrahim, M., Harvey, C.A. y Vargas, B. (2003). Efecto de la cobertura arbórea sobre el comportamiento animal en fincas ganaderas de doble propósito en Matiguás, Matagalpa, Nicaragua. Agroforestería de las Américas, 10(39-40), 47-51.

- Casal, M.T. y Casal, M. (2004). El tratamiento de las enfermedades infecciosas en al-Andalus. Revista Española de Quimioterapia, 17(4), 350-356.

- Castillo, E., Calderón, H., Delgado, V., Flores, Y. y Salvatierra, T. (2006). Situación de los recursos hídricos en Nicaragua. Boletín Geológico y Minero, 117(1), 127-146.

- Castrillón-Estrada, D., Acosta-Vélez, J. y Hernández-Ruiz, E. (2007). Envenenamiento Ofídico. Salud Uninorte, 23(1), 96-111.

- Cerdán, C.R., Rebolledo, M.C., Soto, G., Rapidel, B. y Sinclair, F. (2012). Local knowledge of impacts of tree cover on ecosystem services in smallholder coffee production systems. Agricultural Systems, 110, 119-130.

- Chará, J. (2003). Manual para la evaluación biológica de ambientes acuáticos en microcuencas ganaderas. CIPAV. Cali, Colombia. 76p.

- Chará, J., Pedraza, G., Giraldo, L. e Hincapié, D. (2007). Efecto de los corredores ribereños sobre el estado de quebradas en la zona ganadera del río La Vieja, Colombia. Agroforestería en las Américas, $45,72-78$.

- Cupples, J. (2004). Rural development in El Hatillo, Nicaragua: gender, neoliberalism and environmental risk. Singapore Journal of Tropical Geography, 25(3), 343-357.

- Dagang, A. y Nair, P.K.R. (2003). Silvopastoral research and adoption in Central America: recent findings and recommendations for future directions. Agroforestry Systems, 59, 149-155. 
- Di-Rienzo J.A., Casanoves F., Balzarini M.G., González L., Tablada M. y Robledo C.W. (2012). InfoStat versión 2012. Grupo InfoStat, FCA, Universidad Nacional de Córdoba, Argentina.

- Durán, P. (2006). Misterio y Ministerio del sapo. El Siglo Digital. Ciudad de Panamá, Panamá. Recuperado el 20 de octubre de 2007 de

http://www.elsiglo.com/siglov2/Opinion.php?idnews=9551\&idse c=3\&fechaz=02-01-2006

- Emery, M. y Flora, C. (2006). Spiraling-Up: Mapping Community Transformation with Community Capitals Framework. Journal of the Community Development Society, 37(1), 19-35.

- Fica, A. (2003). Celulitis y erisipela: Manejo en atención primaria. Revista Chilena Infectectología, 20(2), 104-110.

- Flora, C. (2004). Social aspects of small water systems. Journal of Contemporary Water Research \& Education, 128, 6-12.

- Flora, C., Flora, J. y Fey, W. (2004). Rural Communities. US: Westview Press. 372p.

- Fujisaka, S., Holmann, F., Escobar, G., Solórzano, N., Badilla, L., Umaña, L. y Lobo, M. (1997). Sistemas de producción de doble propósito en la región Pacífico Central de Costa Rica: uso de la tierra y demanda de alternativas forrajeras. Pasturas Tropicales, 19(1), 5559.

- Galindo-Uribe, D. y Hoyos-Hoyos, J.M. (2007). Relaciones plantaherpetofauna: nuevas perspectivas para la investigación en Colombia. Universitas Scientiarum, 12, 9-34.

- Garay, N. (1932). Tradiciones y cantares populares de Panamá. Bruselas. pp. 101-114.

- Gómez-Martínez, M.J., Gutiérrez, I., Benjamín, T., Casanoves, F. y DeClerck, F. (2011). Conservación y conocimiento local de herpertofauna en un paisaje ganadero. Agroforestería en las Américas, 48, 65-75.

- Grudens-Schuck, N., Lundy-Allen, B. y Larson, K. (2004). Focus Group Fundamentals. Ames, lowa: lowa State University Extension. Recuperado el 14 de noviembre de 2006 de http://www.extension.iastate.edu/Publications/PM1969B.pdf

- Gutiérrez, I.A. (1996). Aportes de un proyecto de manejo de vida silvestre a la calidad de vida de las poblaciones rurales: el caso de la Cooperativa Omar Baca, Cosigüina, Nicaragua. Tesis Mag. Sc. Turrialba, CR, CATIE. 133p.

- Harvey, C. y Haber, W. (1999). Remnant trees and the conservation of biodiversity in Costa Rican pastures. Agroforestry Systems, 44, 37-68.

- Holdridge, L.R. (1978). Ecología Basada en Zonas de Vida. Serie Libros y Materiales. San José, CR. Educativos IICA No. 34.

- INS (Instituto Nacional de Salud - Perú). (2000). Ofidismo. Serie Documentos Monográficos 10. Lima. 57p.

- Köhler, G. (2001). Anfibios y reptiles de Nicaragua. Herpeton. Frankfurt. 208p.

- $\quad$ (2003). Reptiles de Centroamérica. Herpeton. Frankfurt. $367 p$.

- Larson, K., Grudens-Schuck, N. y Lundy-Allen, B. (2004). Can You Call It a Focus Group? Ames, lowa: lowa State University Extension. Recuperado el 14 de noviembre de 2006 de http://www.extension.iastate.edu/Publications/PM1969A.pdf

- López, F. (2007). Puerto Cabezas Power contamina pozos de agua. El Nuevo Diario, Departamentales, 28 de julio de 2007. 
- Madriz, E. (2000). Focus groups in feminist research. En Denzin, N.K. y Lincoln, Y.S. (eds.). Handbook of qualitative research (pp. 835-850). 2nd ed. Thousand Oaks, CA: Sage.

- Mahecha, L. (2002). El silvopastoreo: una alternativa de producción que disminuye el impacto ambiental de la ganadería bovina. Rev Col Cienc Pec, 15(2), 226-231.

- MARENA (Ministerio del Ambiente y Recursos Naturales). (2002). Estrategia Nacional de Biodiversidad Nicaragua. Managua, NI. 96p.

- . (2004). Resolución ministerial no. 46-2003. Managua, NI. Recuperado el 30 de octubre de 2007 de http://legislacion.asamblea.gob.ni/Normaweb.nsf/(\$AII)/21ADF5E 15B25DEA4062570A100583B99?OpenDocument

- Meyrat, A. (2000). Los ecosistemas y formaciones vegetales de Nicaragua. Protierra/MARENA/CBA. Managua, Nicaragua. 30p.

- MINAE (Ministerio de Ambiente y Energía). (2007). Reglamento para la Evaluación y Clasificación de la Calidad de Cuerpos de Agua Superficiales. San José, CR. Recuperado el 30 de octubre de 2007 de

http://www.hacienda.go.cr/centro/datos/Decreto/Decretos\%2033 903-MINAE-S-

Reglamento\%20para\%20Evaluaci\%C3\%B3n\%20y\%20Clasificaci \%C3\%B3n\%20de\%20Cuerpos\%20agua\%20SuperficialesLa\%20Gaceta\%20178-17\%20SET-2007.pdf

- Munguía, C. y Pérez, W. (2007). Urge hacer pozos en Occidente. La Prensa, 14A, 28 de mayo de 2007.

- Murgueitio, E. (2003). Impacto ambiental de la ganadería de leche en Colombia y alternativas de solución. Livestock Research for Rural Development, 15(10). Recuperado el 5 de noviembre de 2006 de http://www.cipav.org.co/lrrd/Irrd15/10/murg1510.htm

- Murgueitio, E. e Ibrahim, M. (2001). Agroforestería pecuaria para la reconversión de la ganadería en Latinoamérica. Livestock Research for Rural Development, 13. Recuperado el 5 de noviembre de 2006 de http://www.cipav.org.co/lrrd//rrd13/3/murg133.htm

- Naranjo, L. (2003). Sistemas agroforestales para la producción pecuaria y la conservación de la biodiversidad. En Sánchez, M.D. y Rosales, M. Agroforestería para la producción animal en América Latina-II. Estudio FAO. Producción Animal, 155. 34p.

- NRFC (National Rural Funders Collaborative). (2005). Community Capitals, Capacity Building and Outcome Achievement. Recuperado el 28 de octubre de 2006 de http:/lwww.nrfc.org/portal/alias_rainbow/lang_en-

ItabID_3378/DesktopDefault.aspx

- Ocampo, I. y Escobedo, J. (2006). Conocimiento tradicional y estrategias campesinas para el manejo y conservación del agua de riego. Ra Ximhai, 2(2), 343-371.

- ONU. (2005). Género y sistemas de producción campesinos: lecciones de Nicaragua. Roma. 70p.

- Pagiola S., Agostini, P., Gobbi, J., Deán, C., Ibrahim, M., Murgueitio, E., Ramírez, E., Rosales, M. y Ruíz, J. (2004). Pago por servicios de conservación de la biodiversidad en paisajes agropecuarios. Banco Mundial. 50p.

- Pantoja, A. y Córdoba, M. (2007). Batalla por el agua. El Nuevo Diario, 4A, 14 de mayo de 2007.

- Plieninger, T. y Wilbrand, C. (2001). Land use, biodiversity conservation, and rural development in the dehesas of Cuatro Lugares, Spain. Agroforestry Systems, 51(1), 23-34. 
- RAE (Real Academia de la Lengua Española). (2007). Diccionario de la Lengua Española. Vigésima segunda edición. España. Recuperado el 1 de noviembre de 2007 de http://www.rae.com

- Ramírez, A. (2006). Mitos y leyendas: la solución a tus problemas está en la charca. SW Digital, 1. Recuperado el 20 de octubre de 2007 de http://www.seawolves.es/SEPTIEMBRE\%202006.pdf

- Reyes, K.Y. (2006). Análisis del estado de las fuentes de agua para consumo humano y funcionamiento de los acueductos en la cuenca del río La Soledad, Honduras. Tesis Mag. Sc. Turrialba, CR, CATIE.

- Ríos, N., Cárdenas, Y., Andrade, H., Ibrahim, M., Jiménez, F., Sancho, F., Ramírez, E., Reyes, B. y Woo, A. (2007). Escorrentía superficial e infiltración en sistemas ganaderos convencionales y silvopastoriles en el trópico subhúmedo de Nicaragua y Costa Rica. Agroforestería en las Américas, 45, 66-71.

- Ríos, N., Andrade, H. e Ibrahim, M. (2008). Evaluación de la recarga hídrica en sistemas silvopastoriles en paisajes ganaderos. Zootecnia Tropical, 26(3), 183-186.

- Rocha, L. (2002). Cambio en el uso de suelo y factores asociados a la degradación de pasturas en la cuenca del Río Bulbul en Matiguás, Nicaragua. Tesis Mag. Sc. Centro Agronómico Tropical de Investigación y Enseñanza. CATIE, Turrialba, CR. 84p.

- Rodríguez-Acosta, A. (2001). Los venenos y el síndrome de envenenamiento ofídico. VIATE Academia Médica Digital, 9. Recuperado el 20 de octubre de 2007 de http://caibco.ucv.ve/caibco/CAIBCO/Vitae/VitaeNueve/Articulos/ MedicinaTropicall ArchivosPDF/MedicinaTropical.PDF

- Ruíz, F., Gómez, R. y Harvey, CA. (2005). Caracterización del componente arbóreo en los sistemas ganaderos de Matiguás, Nicaragua. TROPITECNICA - NITLAPAN - CATIE. Turrialba, CR. 40p.

- Sánchez, E. (2006). Conocimiento tradicional mazahua de la herpetofauna: un estudio etnozoológico en la Reserva de la Biósfera Mariposa Monarca, México. Estudios Sociales, 14(28), 43-66.

- Savage, J.M. (2002). The amphibians and reptiles of Costa Rica: a herpetofauna between two continents, between two seas. The University of Chicago Press.

- Solórzano, A. (2004). Serpientes de Costa Rica. INBio, San José, CR. 792p.

- Turcios, W.R. (1995). Producción y valoración económica del componente hídrico y forestal de los robledales de altura bajo intervenciones silviculturales. M.Sc.-Tesis, CATIE, Turrialba, Costa Rica. 80p.

- Useche, D.C. (2006). Restauración del paisaje a partir de la implementación de sistemas silvopastoriles para la conservación de la biodiversidad en Nicaragua. Tesis Mag. Sc. Turrialba, CR, CATIE.

- Walsh, B. (1999). Diversidad de ecosistema. En MARENA (Ministerio del Ambiente y Recursos Naturales). Biodiversidad en Nicaragua: un estudio de país (pp. 144-182). Managua, NI.

1. Biólogo. MSc. en Agricultura Ecológica. Laboratorio de Ecoagricultura, Facultad de Ingeniería Agronómica, Universidad del Tolima, Colombia.mjgomez@ut.edu.co 
2. Doctora en Desarrollo Rural. Profesora e Investigadora, Centro Agronómico Tropical de Investigación y Enseñanza - CATIE, Costa Rica.agutie@catie.ac.cr

3. Doctor en Ecología del Paisaje. Profesor e Investigador, Grupo de Ganadería y Manejo del Medio Ambiente (GAMMA), Centro Agronómico Tropical de Investigación y Enseñanza - CATIE, Costa Rica.fdeclerck@catie.ac.cr

4. La estratificación fue realizada por medio de clúster de acuerdo a las siguientes variables: (i) Porcentaje del área agrícola en la finca según usos de suelo. (ii) Hectáreas unidades de trabajo familiar ${ }^{-1}$ (haUTF ${ }^{-1}$ ). (iii) Total de vacas unidad de trabajo familiar ${ }^{-1}$ (vacasUTF ${ }^{1}$ ). (iv) Porcentaje de pastos en la finca. (v) Total días hombres unidad de área ${ }^{-1}$ (dht ha ${ }^{-1}$ ).

5. Los productores se refieren insistentemente a una sentida ausencia de institucionalidad y a la falta de implementación de leyes.

6. Como se afirmó repetidas veces en las conversaciones y entrevistas con los productores.

7. En Costa Rica el Reglamento para la Evaluación y Clasificación de la Calidad de Cuerpos de Agua Superficiales determina para el abastecimiento de agua para uso y consumo humano (Clase 1) permite $<20$ unidades formadoras colonias (UFC), con tratamiento simple de desinfección (MINAE, 2007). En Honduras la Norma Técnica Nacional para la Calidad del Agua Potable no permite la presencia de UFC (Reyes, 2006).

8. Resortera o tirachinas, horquilla con mango a cuyos extremos se unen los de una goma para estirarla y disparar así piedrecillas, perdigones, etc. (RAE, 2007).

9. Pese a que está prohibido el lavado de vehículos y otras actividades, es muy frecuente en el puente del río Bulbul $\left(12^{\circ} 49^{\prime} 36,72^{\prime \prime} \mathrm{N}\right.$ $85^{\circ} 26^{\prime} 12,85^{\prime \prime}$ ) encontrar libremente la realización de esta actividad (observación personal).

10. Pozos perforados, de diámetros reducidos y construcción totalmente mecanizada.

11. 18,47 córdobas por un dólar americano, según la tasa de cambio oficial al 10 de julio de 2007 (BCN, 2007).

12. 18,47 córdobas por un dólar americano, según la tasa de cambio oficial al 10 de julio de 2007 (BCN, 2007).

13. Inflamación infecciosa aguda en placas que afecta la epidermis, ligada generalmente a fiebre, linfangitis, leucocitosis y ocasionalmente adenopatías regionales, típicamente está asociada al Streptococcus pyogenes (Fica, 2003).

14. Sinónimo a zahoríes: personas que detectan manantiales, corrientes subterráneas de agua o incluso sustancias minerales (Ocampo y Escobedo, 2006).

Para citar este artículo: Gómez-Martínez, M. J., Gutiérrez-Montes, I. \& Declerck, F. (2014). Percepción local acerca de la calidad del agua y la herpetofauna en fincas ganaderas del municipio de Matiguás, Nicaragua. Revista Luna Azul, 38, 30-57. Recuperado de http://lunazul.ucaldas.edu.co/index.php?option=content\&task=v iew\&id=893 